\title{
Composition, Repellent and Fumigant Toxicity of Mentha longifolia Essential Oil on Tetranychus urticae and Three Predatory Mites of the Family Phytoseiidae (Acari: Tetranychidae: Phytoseiidae)
}

\author{
F. M. MOMEN ${ }^{1 *}$, M. M. ABDELKADER ${ }^{2}$ and S. F. FAHIM ${ }^{1}$ \\ ${ }^{1}$ Pests and Plant Protection Department, National Research Centre (NRC), 31 El-Bohouth Street, 12622 Dokki, \\ Cairo, Egypt \\ ${ }^{2}$ Departments of Entomology, Faculty of Science, Ain Shams University, Cairo, Egypt
}

(Received: 20 February 2018; accepted: 3 May 2018)

\begin{abstract}
The chemical composition of essential oil extracted from leaves of the medicinal plant Mentha longifolia (L.) Huds growing in Egypt, were determined through Gas Chromatography/Mass Spectrometry (GC/ MS). The analyses revealed that the major component of $M$. longifolia was Monterpene ketone (piperitone oxide). Mentha longifolia was potent for the pest Tetranychus urticae Koch with a significant increase in repellency. In addition, it exhibited strong oviposition deterrence to the pest based on a $99.4 \%$ reduction of the total number of eggs on leaf discs treated with the oil. The $\mathrm{LC}_{50}$ values of $M$. longifolia against eggs, nymphs and females of $T$. urticae by fumigant application, were $2.95,3.47,3.74 \mu \mathrm{L} / \mathrm{L}$, while the $\mathrm{LC}_{90}$ values were 8.99 , 9.41, $11.01 \mu \mathrm{L} / \mathrm{L}$, respectively.

The toxicity of $M$. longifolia oil by fumigant application to females and eggs of 3 predatory phytoseiid mites was tested. Neoseiulus californicus (McGregor) is extremely insusceptible to M. longifolia oil than the pest T. urticae and both phytoseiid mites, Neoseiuls barkeri (Hughes) and Typhlodromips swirskii (Athias Henriot) under laboratory conditions. When both stages of tested predatory mites, exposed to fumigant of $\mathrm{LC}_{50}$ and $\mathrm{LC}_{90} \mu \mathrm{L} / \mathrm{L}$ values reported on $T$. urticae, female's mortality of $N$. californicus was lesser than that reported on N. barkeri and T. swirskii.

These show that the fumigant toxicity of $M$. longifolia oil has the highest lethal activity to the pest T. urticae and the least to the predatory mite $N$. californicus. Results indicated that the mode of delivery of the essential oil was largely a result of action in the vapor phase via respiratory system. Data was suggested that M. longifolia oil have the potential agent to be used in the maintainable management of T. urticae combined with $N$. californicus.
\end{abstract}

Keywords: Essential oil, Mentha longifolia, Tetranychus urticae, predatory phytoseiid mites, toxicity.

Tetranychus urticae Koch (Acari: Tetranychidae) is one of the greatest severe pest species infested many fruit tree, cotton, vegetables and a variety of greenhouse crops. This pest cause a small acne on the higher side of the leaf as a results of chlorophyll reduction, webbing, dry leaf-fall, up to necrosis in young leaves and stems, or even the plant death

\footnotetext{
* Corresponding author; e-mail: fatmomen@yahoo.com
} 
in a severe mite-infestation (van der Geest, 1985). The complexity to manage this pest is its talent to build up multiple resistances to many acaricides (Lee et al., 2003; Kim et al., 2006). Besides, the broad uses to the synthetic pesticide cause an unpleasant effect on human being, predators as well parasites and the environment (Kumral et al., 2010).

Predatory phytoseiid mites were used in the control of pest mites in the field and greenhouses (McMurtry and Croft, 1997). Regardless of its action in controlling the pest, predatory mites cannot competent, to keep the pest population below the injure level and their sensitivity to the majority of chemical pesticides was an additional problem (Miresmailli and Isman, 2006).

The efficacious control of T. urticae is hard to succeed by only a single control method (Rhodes and Liburd, 2006). Therefore, combination of various control programs concerned, using selective release of single / multi-predators and relatively secure acaricides on these beneficial mites, this may bring an excellent control of T. urticae in the field (Rhodes et al., 2006). Both chemical and biological control agent may give benefits, which are relatively cheaper and more efficient to control pest mites than that provided by using chemical alone (Hosny et al., 2003).

Therefore, there is vital require to expand competent, secure and ecologically pleasant pesticides such as natural oil, to replace the conventional synthetic materials. However, the plant essential oils were suggested to be a good source of these alternative natural pesticides because their novel mode of actions includes its low toxicity to the beneficial organisms and low phytotoxicity (Isman, 2006). Taking into account that, the identifying a selective natural oil to be use in IPM program is very important to guard the predatory mites and reduce the environmental pollution.

Numerous essential oils of aromatic plants belonging to various families such as Lamiaceae, Asteraceae and Zingiberaceae have been cited to have a variety of biological activities against pest mites including repellence, feeding and oviposition deterrence and toxicity (Calmasur et al., 2006; Motazedian et al., 2012).

Neoseiulus barkeri (Hughes), Neoseiulus californicus (McGregor) and Typhlodromips swirskii (Athias-Henriot) are the main predators of pest mites and are widely found on various crops. Both N. barkeri and T. swirskii are generalist endogenous predators and they were able to control mite and insect pests of various families such as Tetranychiidae, Eriophyidae, Thripidae and Aleyrodidae (Hansen, 1988; Momen, 1995; Momen and Abdel-Khalek, 2008; Wimmar et al., 2008); N. californicus being specialist on Tetranychus sp. (McMurtry and Croft, 1997).

Although insecticidal activity of plant essential oils has well been documented by various authors; little intensive work has been published in relation to the activity of aromatic plants (oil/extract) on the tetranychid pests and its predatory phytoseiid mites (Choi et al., 2004; Miresmailli and Isman, 2006; El-Sharabasy, 2010; Han et al., 2010; Momen et al., 2014).

The present study has four objectives:

1) To determine the main component identified by GC/MS of an indigenous Egyptian plant, Mentha longifolia (L.) Huds (family Lamiacae) which is cultivated allover Egypt.

2) To test under laboratory conditions the level of activity of $M$. longigolia on various stages of the pest $T$. urticae and its behavior aspects through repellency and oviposition deterrence. 
3) To test under laboratory conditions the toxicity of M. longigolia on various stages of the pest $T$. urticae in addition to test its repellency and oviposition deterrence activity against the pest.

4) Mortality level of tested predators were also investigated when they are sprayed by 2 efficient oil doses on the pest T. urticae.

\section{Materials and Methods}

\section{Plant material}

The aerial parts of $M$. longifolia was collected from plant originally grown in the Experimental Farm of (NRC) at Giza Governorate to obtain the essential oils.

\section{Preparation of Mentha longifolia oil}

The air-dried plant material (aerial parts) was pulverized and the essential oils isolated after hydro-distillation for $4 \mathrm{~h}$ in a steam distillation using a Clevenger apparatus. The oil collected was dehydrated over anhydrous sodium sulfate and subjected to GC/MS analysis.

\section{Chromatographic investigation of the volatile oil}

The obtained essential oil was subjected for GC/MS analysis under the following conditions:

GC/MS analyses were performed on a Thermo Scientific capillary gas chromatography (model Trace GC ULTRA) directly coupled to ISQ Single Quadruple MS. TG-5MS non-polar 5\% Phenyl Methyl polysiloxane capillary column $(30 \mathrm{~m} \times 0.25 \mathrm{~mm}$ ID $\times 0.25 \mathrm{um}$ ) was used under the following conditions: oven temperature program from $40{ }^{\circ} \mathrm{C}$ (3 min) to $280{ }^{\circ} \mathrm{C}$ at $5{ }^{\circ} \mathrm{C} / \mathrm{min}$, then isothermal at $280{ }^{\circ} \mathrm{C}$ for $5 \mathrm{~min}$; carrier gas Helium, flow rate $1 \mathrm{~mL} / \mathrm{min}$; the volume of injected sample was $1 \mu 1$ of sample in diethyl ether; splitless injection technique; ionization energy $70 \mathrm{eV}$, in the electronic ionization (EI) mode.

\section{Identification of components}

The components were identified based on the comparison of their relative retention time and mass spectra with those of standards, a computer library data of the GC/MS system and literature data (Adams, 2001).

\section{Preparation of the primary emulsions}

The primary emulsions of $M$. longifolia were in repellency test prepared by mixing of Triton-X 100. Different concentrations of this emulsion were prepared and tested against $T$. urticae. 
Stock culture of the pest Tetranychus urticae

The colony was kept at $28 \pm 2{ }^{\circ} \mathrm{C}$ and $70 \pm 5 \%$ relative humidity on kidney bean (Phaseolus vulgaris) plant without any exposure to any pesticides until they were used in experiments. The fresh un-infested kidney bean plants with four / five leaves were sited between the bean plants infected with $T$. urticae for $48 \mathrm{~h}$. During this time, adults would move on to the un-infested plants, and the mites relocated to fresh bean leaves were used in subsequent experiments.

\section{Rearing of the predatory mite species}

Three phytoseiid species, i.e. N. barkeri, N. californicus and T. swirskii, were tested. Adult females of $N$. barkeri and T. swirskii were collected from heavily infested cucumber leaves in Giza Province of Egypt, while N. californicus used in the present study imported from France in 1999 and being established in most of agroecosystem in Egypt.

The stock colony of each predatory mite was maintained separately on leaves of kidney bean infested with mixed stages of T. urticae as prey. Each leaf was placed underside up on a wet cotton wool layer in a Petri dish (6 cm diameter), a water-saturated cotton strip was placed around the leaf margin to prevent escaping mites and to maintain the leaf fresh. Water supply was added daily and Petri dishes were kept in an incubator at $28 \pm 2{ }^{\circ} \mathrm{C}, 70 \pm 5 \%$ R.H. and L16: D8 h photoperiod. Predators were transferred to new and fresh infested leaf discs with T. urticae weekly to keep the culture healthy.

\section{Repellency and oviposition deterrence activity for Tetranychus urticae females}

Kidney bean leaf discs $(4.5 \mathrm{~cm}$ in diameter) were placed with the lower surface upwards in a Petri dish lined with moist cotton wool. During the pre-experiments of each test using the oil, we were selected five constrictions in repellency test. According to pre-experiments, one-half of each disc was painted separately with selected concentrations of Mentha oil, while the other half served as a control. Twenty newly emerged females of T. urticae were introduced into the middle of each leaf disc. Each treatment comprised 5 replicates and repeated twice. Adult females were placed on the midrib and observations on repellency and oviposition were taken after 0.5, 1, 2, 4, 6 and $24 \mathrm{~h}$ after treatment, respectively. The deterrence index (DI) (mites which had left the treated sections were considered as repelled) was calculated according to Pascual and Robledo (1998). The number of eggs laid on both sides and the percentage mortality of adult females were recorded after $24 \mathrm{~h}$. Mites found in the neutral area during the evaluation were considered as repelled or attracted based on their proximity to the control or to the treatment.

\section{Treatments}

Fumigant toxicity to egg, nymphal and female stages of the pest Tetranychus urticae

To obtain newly laid $T$. urticae eggs, females were placed on kidney bean discs ( $3 \mathrm{~cm}$ diameter), with a fine brush and allowed to lay eggs for $24 \mathrm{~h}$, after which time, 
females removed with aspirator. Leaf disks with eggs (0-24 h-old), mixed nymphal stages / females (2-3 d old) were placed on water-soaked cotton pads on glass chamber $(9-\mathrm{cm}$ long and $2.5-\mathrm{cm}$ height). Various concentrations of oil were prepared by dissolving the requisite amounts in acetone, and then applied to filter papers. After drying in a fume hood for $2 \mathrm{~min}$, each treated filter paper was attached to the downside of a lid with solid glue. It did not affect adversely $T$. urticae. The chamber was covered with lid. The mite-chambers were sealed with Par-film to prevent losing of the essential oils from the mite chamber. This prevented direct contact of tested various stages of T. urticae with the Mentha oil. Each treatment consisted of four concentrations, each with 4 replicates of the essential oil (25 eggs / nymphs / females / replicate were tested) and a control. All treatments were repeated twice. The control consisted of the same number of mites as the treatments; and was kept under the same conditions on leaf discs which not treated with any essential oil. Experiments were performed at $28 \pm 2{ }^{\circ} \mathrm{C}, 70 \pm 5 \%$ R.H. and $16 \mathrm{~L}: 8 \mathrm{D}$-h photoperiod. To determine mortality, nymphal and female stages were touched with the tip of a fine hairbrush after $48 \mathrm{~h}$. If the mite did not move, it was considered dead. The exposure period for assessing the ovicidal effects of the essential oil was $72 \mathrm{~h}$ for egg stage and $48 \mathrm{~h}$ for nymphal and female stages. Evaluation of the ovicidal action was based on hatching rate at each concentration.

\section{Fumigant toxicity to egg and female stages of the predatory mites}

Typhlodromips swirskii, Neoseiulus californicus and Neoseiulus barkeri

Ten females of each predatory mite were transferred to the lower surface of $P$. vulgaris discs (3-cm in diameter) and left to oviposit for $24 \mathrm{~h}$ and removed thereafter. Leaf discs with eggs (0-24 h-old) / females (2-3 days-old) were resting on wet cotton pads in glass chamber (9-cm long and $2.5-\mathrm{cm}$ height). Various concentrations of M. longifolia oil were prepared and used as above. Four concentrations each with 4 replicate ( 25 eggs/ females / replicate) were tested. All treatments were repeated twice. Mortality were recorded after $48 \mathrm{~h}$ for each predatory mite.

Efficiency of Mentha longifolia oil ( $L C_{50}$ and $L C_{90}$ values reported on the pest Tetranychus urticae) against eggs and females of the predatory mites, Typhlodromips swirskii, Neoseiulus californicus and Neoseiulus barkeri

Two concentrations $\left(\mathrm{LC}_{50}\right.$ and $\mathrm{LC}_{90}$ values that reported on T. urticae from its toxicity lines) were tested against the predatory mites to test if these concentrations are toxic or not to the tested predatory mites.

Ten females of each predatory mite were transferred to kidney bean leaf discs (3-cm in diameter) and allowed to oviposit for $24 \mathrm{~h}$, which were then removed. Leaf discs with eggs (0-24 h-old) / females (2-3 days-old) were resting on wet cotton pads in glass chamber (9-cm long and $2.5-\mathrm{cm}$ height). Two concentrations $\left(\mathrm{LC}_{50}\right.$ and $\mathrm{LC}_{90}$ values reported on T. urticae) of M. longifolia oil were prepared and used as the method described above. Four replicates (25 eggs / females / replicate) were used / concentration. All treatments were repeated twice. Mortality were recorded after $48 \mathrm{~h}$ for each predatory mite. In each test, a control was included. 


\section{Statistical analysis}

- The percentages of eggs, nymphs and females mortalities were calculated according to Abbott's formula (1925).

- The deterrence index (DI) was calculated using the following formula (Pascual and Robledo, 1998):

$$
\mathrm{DI}=\left[\frac{\text { Control-Test }}{\text { Control+Test }}\right] \times 100 \%
$$

Control $=$ the number of specimens in the control.

Test $=$ the number of specimens in the treated.

- The oviposition deterrence index (ODI) was calculated according to Lundgren (1975).

$$
\mathrm{ODI}=\left[\frac{\mathrm{B}-\mathrm{A}}{\mathrm{B}+\mathrm{A}}\right] \times 100
$$

$\mathrm{B}=$ number of eggs in the control.

$A=$ number of eggs in the treated.

* In repellency test, the differences between the tested concentrations and between the observation times in the number of $T$. urticae distributed on the treated leaf sections were studied using analysis of variance (ANOVA) and means were separated by Duncan's multiple range test (DMRT). In addition, the differences between the treated and untreated leaf sections in the number of eggs deposited / female were analyzed by T-test.

\section{Results}

Gas chromatography / mass spectrometry (GC / MS) analysis

The GC / MS analysis revealed that the main components identified from M. longifolia oil were piperitone oxide $(83.32 \%)$, piperitenone oxide $(4.80 \%)$, 2-methyl-5-(1methylethyl) phenol $(2.29 \%)$, and caryophyllene $(1.58 \%)$. These four main components represented about $91.99 \%$ of the total Mentha oil content. All the chemical compounds identified in Mentha oil are shown in (Table 1).

Repellency and oviposition deterrence activity on Tetranychus urticae females

The essential oil of M. longifolia was repelled T. urticae females in all tested concentration and the deterrence index (DI) ranged from (82.00-98.00\%).

With the exception of the concentration $0.3 \%$, and among the different observation periods, insignificant differences were shown in the number of distributed T. urticae females on treated part (Table 2). The total number of eggs deposited by female T. urticae after $24 \mathrm{~h}$ of treatment was significantly lower on treated leaf sections with different concentrations of Mentha oil than on those of the untreated ones (Table 2). 
Table 1

Percentage of chemical component identified in the essential oil of Mentha longifolia leaves by GC/MS

\begin{tabular}{|c|c|c|c|c|}
\hline No & Compound identified & R.t. & (\%) Area & Class \\
\hline 1 & 2,5-Diethyltetrahydrofuran & 6.09 & 0.05 & Other derivative \\
\hline 2 & Alpha-Pinene & 7.33 & 0.51 & Monoterpenes \\
\hline 3 & 2-Beta-Pinene & 8.87 & 0.60 & Monoterpene \\
\hline 4 & Beta-Myrcene & 9.64 & 0.39 & Monoterpene (Hydrocarbon) \\
\hline 5 & 3-Octanol & 9.84 & 0.27 & $\begin{array}{l}\text { Ethylamylcarbinol (fatty tertiary } \\
\text { alcohol) }\end{array}$ \\
\hline 6 & 1,8-Cineole & 10.96 & 0.68 & Monoterpenoid \\
\hline 7 & 3,7-Dimethyl-1,3,6-Octatriene & 11.45 & 0.41 & Monoterpenes \\
\hline 8 & Isomyl-2-methylbutyrate & 13.82 & 0.47 & Other derivative \\
\hline 9 & Cyclobutanecarboxylic acid, octyl ester & 14.76 & 0.73 & $\begin{array}{l}\text { Aromatic Carboxylic Acids } \\
\text { (Cycloalkanes) }\end{array}$ \\
\hline 10 & Piperitone oxide & 19.20 & 83.32 & Monoterpene ketone \\
\hline 11 & 2-Methyl-5-(1-methylethyl)Phenol & 20.66 & 2.29 & $\begin{array}{l}\text { Monoterpenoid phenol } \\
\text { (cymophenol) }\end{array}$ \\
\hline 12 & $\begin{array}{l}\text { 3-Methyl-6-(1-methylethylidene)-2- } \\
\text { Cyclohexen-1-one }\end{array}$ & 21.91 & 0.28 & Monoterpenoid (piperitenone) \\
\hline 13 & Piperitenone oxide & 22.85 & 4.80 & Monoterpenoid ketone \\
\hline 14 & $\begin{array}{l}\text { Tetrahydro-3-methyl-6-propyl-2H- } \\
\text { Pyran-3-ol, acetate }\end{array}$ & 23.39 & 0.30 & Other derivative \\
\hline 15 & $\begin{array}{l}\text { 2-(2-butenyl)-4-hydroxy-3-methyl-2- } \\
\text { Cyclopenten-1-one }\end{array}$ & 23.87 & 0.59 & Other derivative \\
\hline 16 & Caryophyllene & 24.49 & 1.58 & Natural bicyclic Sesquiterpenes \\
\hline 17 & Alpha-Humulene & 25.52 & 0.14 & Monocyclic Sesquiterpenes \\
\hline 18 & Beta-Farnesene & 25.83 & 0.46 & Sesquiterpenes \\
\hline 19 & 4-Chloro-2,3-dimethyl-1,3-hexadiene & 26.05 & 0.36 & Other derivative \\
\hline 20 & Germacrene-D & 26.38 & 0.72 & $\begin{array}{l}\text { Sesquiterpenes (volatile organic } \\
\text { hydrocarbons) }\end{array}$ \\
\hline 21 & Gamma-Elemene & 26.84 & 0.57 & Sesquiterpenes \\
\hline 22 & Spathulenol & 29.15 & 0.21 & Other derivative \\
\hline \multirow[t]{2}{*}{23} & Alpha-Cadinol & 30.95 & 0.25 & Sesquiterpenes (Prenol Lipids) \\
\hline & & & 99.98 & \\
\hline
\end{tabular}

Compounds listed in order of R.t. (retention times)

The highest oviposition deterrence index (ODI) value was detected on $1 \%$ concentration $(99.43 \%)$, while $0.3 \%$ concentration being recorded the lowest ODI value (97.60\%), respectively (Table 2 ).

Fumigant toxicity to egg, nymphal and female stages of the pest Tetranychus urticae

Based on the $\mathrm{LC}_{50}$ and $\mathrm{LC}_{90}$ values of $M$. longifolia oil on various stages of T. urticae, the egg was the most sensitive stage, while the female being the least one (Table 3 ). 


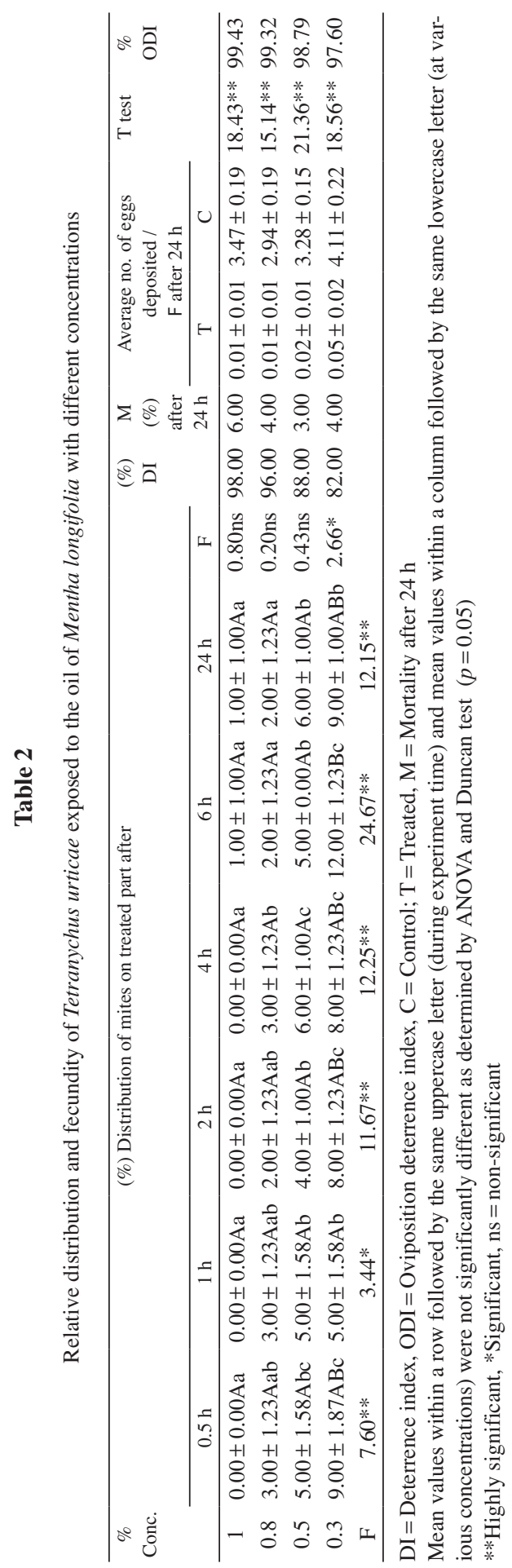


Fumigant toxicity to egg and female stages of the predatory mites Typhlodromips swirskii, Neoseiulus californicus and Neoseiulus barkeri

The $\mathrm{LC}_{50}$ and $\mathrm{LC}_{90}$ values of Mentha oil for $N$. barkeri females at $48 \mathrm{~h}$ post-treatment were 3.66 and $9.63 \mu \mathrm{L} / \mathrm{L}$, respectively. Results indicated that $N$. californicus females was the most insusceptible predatory mite $\left(\mathrm{LC}_{50}=5.01\right.$ and $\left.\mathrm{LC}_{90}=13.78 \mu \mathrm{L} / \mathrm{L}\right)$ while $T$. swirskii females had the least insusceptibility to Mentha oil (Table 4). Likewise, eggs of $N$. californicus was the most insusceptible predatory eggs to $M$. longifolia oil while, $N$. barkeri eggs being the least insusceptible one (Table 4).

Efficiency of Mentha longifolia oil ( $L C_{50}$ and $L C_{90}$ values reported on the pest Tetranychus urticae) against eggs and females of the predatory mites, Typhlodromips swirskii, Neoseiulus californicus and Neoseiulus barkeri

Based on both concentrations used with Mentha oil, results indicated that: the lowest percentage of mortality was recorded in $N$. californicus females and eggs while the highest mortality being recorded in both stages of $N$. barkeri (at $\mathrm{LC}_{90}$ of Mentha oil), respectively (Table 5).

Table 3

Fumigant effect of Mentha longifolia essential oil on various stages of the pest Tetranychus urtica

\begin{tabular}{lcccc}
\hline \multicolumn{1}{c}{ Tetranychus urticae } & $\mathrm{LC}_{50} \mu \mathrm{L} / \mathrm{L}$ & Fiducial limits for $\mathrm{LC}_{50}$ & $\begin{array}{c}\mathrm{LC}_{90} \\
\mu \mathrm{L} / \mathrm{L}\end{array}$ & Slope \pm S.E. \\
\hline Females & 3.74 & $3.29-4.20$ & 11.01 & $2.73 \pm 0.23$ \\
Nymphs & 3.47 & $3.06-3.89$ & 9.41 & $2.96 \pm 0.26$ \\
Eggs & 2.95 & $2.54-3.38$ & 8.99 & $2.65 \pm 0.34$ \\
\hline
\end{tabular}

Table 4

Efficiency of Mentha longifolia oil on egg and female stages of the predatory mites, Neoseiulus barkeri, Neoseiulus californicus and Typhlodromips swirskii

\begin{tabular}{|c|c|c|c|c|c|}
\hline 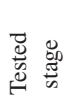 & Predatory mite & $\begin{array}{l}\mathrm{LC}_{50} \\
\mu 1 / \mathrm{L}\end{array}$ & $\begin{array}{c}\text { Fiducial } \\
\text { limits for } \mathrm{LC}_{50}\end{array}$ & $\begin{array}{l}\mathrm{LC}_{90} \\
\mu \mathrm{1} / \mathrm{L}\end{array}$ & Slope \pm S.E. \\
\hline \multirow{3}{*}{$\begin{array}{c}\frac{\mathscr{d}}{\tilde{J}} \\
\stackrel{\Xi}{0} \\
\text { II }\end{array}$} & N. barkeri & 3.66 & $3.24-4.09$ & 9.63 & $3.045 \pm 0.27$ \\
\hline & N. californicus & 5.01 & $4.47-5.63$ & 13.78 & $2.92 \pm 0.25$ \\
\hline & T. swirskii & 3.41 & $2.93-3.90$ & 11.61 & $2.41 \pm 0.24$ \\
\hline \multirow{3}{*}{$\begin{array}{l}60 \\
600 \\
60 \\
\text { [I }\end{array}$} & N. barkeri & 3.01 & $2.57-3.47$ & 9.93 & $2.47 \pm 0.33$ \\
\hline & N. californicus & 4.51 & $3.97-5.11$ & 14.03 & $2.60 \pm 0.24$ \\
\hline & T. swirskii & 3.33 & $2.87-3.83$ & 10.73 & $2.52 \pm 0.33$ \\
\hline
\end{tabular}


Table 5

Efficiency of Mentha longifolia oil ( $\mathrm{LC}_{50}$ and $\mathrm{LC}_{90}$ values of T. urticae ${ }^{*}$ ) on females and eggs of the predatory phytoseiid mites, Neoseiulus barkeri, Neoseiulus californicus and Typhlodromips swirskii

\begin{tabular}{|c|c|c|c|c|c|c|}
\hline \multirow{3}{*}{$\begin{array}{c}\text { Concentration* } \\
\mu \mathrm{L} / \mathrm{L}\end{array}$} & \multicolumn{6}{|c|}{$\%$ of corrected mortality** } \\
\hline & \multicolumn{2}{|c|}{ N. barkeri } & \multicolumn{2}{|c|}{ N. californicus } & \multicolumn{2}{|c|}{ T. swirskii } \\
\hline & Females & Eggs & Females & Eggs & Females & Eggs \\
\hline $\mathrm{LC}_{50}$ & 47.92 & 56.04 & 35.42 & 43.78 & 52.11 & 57.07 \\
\hline $\mathrm{LC}_{90}$ & 91.15 & 90.11 & 77.60 & 80.00 & 86.84 & 89.13 \\
\hline
\end{tabular}

$* \mathrm{LC}_{50}$ and $\mathrm{LC}_{90}$ values that recorded on $T$. urticae from its toxicity line

**Corrected mortality calculated using Abbott's formula

\section{Discussion}

Essential oils contain well complex combinations of hydrocarbons such as terpenes (monoterpenes, sesquiterpenes and diterpenes) and oxygenated compounds such as esters, ketones and alcohols phenols (Isman, 2006). Biological activity is affected by exchanges among structural component in the essential oil. Even insignificant compounds can have a serious function due to joined effects, additive action between chemical classes and synergy or antagonism (Attia et al., 2011).

Like many essential oils, $M$. longgifolia proved to have adulticidal, ovicidal, repellent, antifeedant and killing behavior against T. urticae. Similar to our results, Choi et al. (2004) and Han et al. (2010), indicated that many essential oils are effective against eggs and females of $T$. urticae lacking direct contact but by fumigant, resulted mode of delivery of the oil was largely caused by action in the vapor phase via the respiratory system.

Mentha longifolia oil was more effective against $T$. urticae than the predatory mite $N$. californicus. El-Sharabasy (2010) found that the $\mathrm{LC}_{50}$ value of ethanolic extract of A. judaica against $P$. persimilis was very low $(167.3 \mathrm{gm} / \mathrm{ml})$ as compared to the $\mathrm{LC}_{50}$ value of adult $T$. urticae which being $0.29 \mathrm{gm} / \mathrm{ml}$. Moreover, effectiveness of other different $A$. judaica leaf extracts on $P$. persimilis mite was very low as compared to T. urticae. Neoseiulus californicus was 1-2 times more tolerant than T. urticae to 10 plant essential oils using direct spray or vapor-phase mortality bioassays (Han et al., 2010). In addition, with the exception of caraway seed, clove and basil oils, there were insignificant differences in toxicities between T. urticae and N. californicus with the other seven tested oils.

The essential oil of Mentha holds good mite repellency against T. urticae females. This action might due to the main components as piperitone oxide (Monoterpene ketone) as well as some other components. Monoterpenes have been well known as forceful fumigants, repellents, and insecticides toward stored-product insects (Papachristos et al., 2004). Given that the plant essential oil (Ariel part) is traditionally used in folk medicine, the oil can be considered safe for the health. On the other hand, the influence of oil on beneficial organisms like predatory mites was quite safe.

The essential oil from $M$. longifolia could become a practical substitute to conventional chemical control approaches. However, further studies need to be conducted in order to evaluate the safety of this oil before practical use in T. urticae control.

More work is essential to evaluate the cost / benefits of $M$. longifolia oil on wide scale to control the pest $T$. urticae in commercial greenhouses. 


\section{Literature}

Abbott, W. S. (1925): A method of computing the effectiveness of an insecticide. J. Econ. Entomol. 18, $265-267$.

Adams, R. P. (2001): Identification of essential oil components by gas chromatography/quadrupole mass spectroscopy. Allured Publishing Corporation, Carol Stream, $455 \mathrm{p}$.

Attia, S., Grissa, K. L., Lognay, G., Heuskin, S., Mailleux, A. C. and Hance, T. (2011): Chemical composition and acaricidal properties of Deverra scoparia essential oil (Araliales: Apiaceae) and blends of its major constituents against Tetranychus urticae (Acari: Tetranychidae). J. Econ. Entomol. 104, 1220-1228.

Calmasur, O., Aslan, I. and Sahin, F. (2006): Insecticidal and acaricidal effect of three Lamiaceae plant essential oils against Tetranychus urticae Koch and Bemisia tabaci Genn. Ind. Crop. Prod. 23, 140-146.

Choi, W. I., Lee, S. G., Park, H. M. and Ahn, Y. J. (2004): Toxicity of plant essential oils to Tetranychus urticae (Acari: Tetranychidae) and Phytoseiulus persimilis (Acari: Phytoseiidae). J. Econ. Entomol. 97, 553-558.

El-Sharabasy, H. M. (2010): Acaricidal activities of Artemisia judaica L. extract against Tetranychus urticae Koch and its predator Phytoseiulus persimilis Athias-Henriot (Tetranychidae: Phytoseiidae). J. Bio. 3, 514-519.

Han, J., Choi, B., Lee, S., Kim, S. and Ahn, Y. (2010): Toxicity of plant essential oils to acaricide susceptible and -resistant Tetranychus urticae (Acari: Tetranychidae) and Neoseiulus californicus (Acari: Phytoseiidae). J. Econ. Entomol. 103, 1293-1298.

Hansen, L. S. (1988): Control of Thrips tabaci (Thysanoptera: Thripidae) on glasshouse cucumber using large introductions of predatory mite Amblyseius barkeri (Acarina: Phytoseiidae). Entomophaga 33, 33-42.

Hosny, A. H., Keratum, A. Y., EL-Naggar, M. M. F. and Magouz, R. I. (2003) Laboratory and field evaluation of environmentaly safe chemicals against the two-spotted spider mite Tetranychus urticae Koch and it's predatory mite Amblyseius gossipi. J. Pest Con. Env. Sci. 11, 87-104.

Isman, M. B. (2006): Botanical insecticides, deterrents, and repellents in modern agriculture and an increasingly regulated world. Ann. Rev. Ent. 51, 45-66.

Kim, Y. J., Park, H. M., Cho, J. R. and Ahn, Y. J. (2006): Multiple resistance and biochemical mechanisms of pyridaben resistance in Tetranychus urticae. J. Econ. Entomol. 99, 954-958.

Kumral, N. A., Cobanoglu, S. and Yalcin, C. (2010): Acaricidal, repellent and oviposition deterrent activities of Datura stramonium L. against adult Tetranychus urticae (Koch). J. Pest Sci. 83, 173-180.

Lee, Y., Song, M., Ahn, K., Lee, K., Kim, J. and Kim, G. (2003): Monitoring of acaricides resistance in two-spotted spider mite (Tetranychidae) populations from rose green-house in Korea. J. Asia-Pac. Ent. 6, 91-96.

Lundgren, 1. (1975): Natural plant chemicals acting as oviposition deterrents on cabbage butterflies Pierisbrassicae (1.), Pierisrapae (1.) and Pierisrapi (1.). Zoo Sci. 4, 253-258.

McMurtry, J. A. and Croft, B. A. (1997): Life-styles of phytoseiid mites and their roles in biological control. Ann. Rev. Ent. 42, 291-321.

Miresmailli, S. and Isman, M. B (2006): Efficacy and persistence of rosemary oil as an acaricide against two spotted spider mite (Acari: Tetranychidae) on greenhouse tomato. J. Econ. Entomol. 99, 2015-2023.

Momen, F. M. (1995): Feeding, development and reproduction of Amblyseius barkeri (Acarina: Phytoseiidae) on various kinds of food substances. Acarologia 36, 101-105.

Momen, F. M. and Abdel-Khalek, A. (2008): Effect of the tomato rust mite Aculops lycopersici (Acari: Eriophyidae) on the development and reproduction of three predatory phytoseiid mites. Int. J. Trop. Ins. Sci. $28,53-57$.

Momen, F. M., Abdel Rahman, H. A., Samour, E. A., Aly, S. M. and Fahim, S. F. (2014): Acaricidal activity of Melissa officinalis oil and its formulation on Tetranychus urticae and the predatory mite Neoseiulus californicus (Acari: Tetranychidae and Phytoseiidae). Acta Phytopathol. et Entomol. Hung. 49, 95-115.

Motazedian, N., Ravan, S. and Bandani, A. R. (2012): Toxicity and repellency effects of three essential oils against Tetranychus urticae Koch (Acari: Tetranychidae). J. Agr. Sci. Tech. 14, 275-284.

Papachristos, D. P., Karamanoli, K. I., Stamopoulos, D. C. and Menkissoglu-Spiroudi, U. (2004): The relationship between the chemical composition of three essential oils and their insecticidal activity against Acanthoscelides obtectus (Say). Pest Man. Sci. 60, 514-520.

Pascual, V. M. J. and Robledo, A. (1998): Screening for anti-insect activity in Mediterranean plants. Ind. Crop Prod. 8, 183-194. 
Rhodes, E. M. and Liburd, O. E. (2006): Evaluation of predatory mites and Acramite for control of two spotted spider mites in strawberries in north-central Florida. J. Econ. Entomol. 99, 1291-1298.

Rhodes, E. M., Liburd, O. E., Kelts, C., Rondon, S. I. and Francis, R. R. (2006): Comparison of single and combination treatments of Phytoseiulus persimilis, Neoseiulus californicus, and Acramite (bifenazate) for control of two spotted spider mites in strawberries. Exp. Appl. Acarol. 39, 213-225.

van der Geest, L. P. S. (1985): Aspects of physiology. World crop pests: In: W. Helle and M. W. Sabelis (eds): Spider Mites. Their Biology, Natural Enemies and Control. Vol. 1A, Elsevier, Amsterdam, The Netherlands, pp. 171-182.

Wimmar, D., Hoffmann, D. and Schausberger, P. (2008): Prey suitability of western flower thrips, Frankliniella occidentalis and onion thrips, Thrips tabaci, for the predatory mite Amblyseius swirskii. Bio. Sci. Tech. $18,541-550$. 